\title{
Simulation in Cinema
}

\author{
By Temenuga Trifonova
}

Spring 2004 Issue of KINEMA

\section{SPECIAL EFFECTS: SIMULATION IN CINEMA}

There are perhaps two main reasons for the resentment many film critics feel for special effects: first, special effects distract the viewer from the supposedly most substantial aspect of the film, narrative; second, special effects present a danger to what is assumed to be the essential realism of film. New digital technologies, so the argument goes, corrupt the purity of the filmic image:

Image manipulation through external montage is one matter, in which shots are intercut for emotional or associative impact. But Digital Domain, ILM, and their brethren are creating a new sort of montage montage within the frame, without the familiar warning, or 'limit' signals we have been trained to look for (wipes, matte lines, differences in film stock grain, inaccurate image-sizing and other flaws). These visual clues alerted us to the artificiality and the constructed-ness of the manufactured image we see on the screen; now these clues are absent. Images within images are nothing new. Images seamlessly bonded to images within the same frame are a different matter altogether. (Wheeler 32)

Supposedly, film once existed in a pure, natural state, which is now threatened by new developments in digital technology such as CGI (computer-generated imagery). According to this kind of reasoning, film is natural or real as long as we know that it is artificial. Conversely, once we are no longer aware of any manipulation of the filmic image precisely because of the perfection of manipulation, film becomes 'unreal' or 'unnatural'. In the passage cited above Wheeler does not object to the digital manipulation of the relationship between images since he considers this relationship external to the images themselves (external montage); what he objects to is the manipulation of the intrinsic nature of the image (internal montage). He is seriously concerned that digital manipulation renders an image external to itself, thus undermining its reality, which is assumed to depend on the self-sufficiency of the image. An image becomes a spectacle, a simulacrum, when it is no longer possible to distinguish between the inside and the outside of the image, between what is constitutive of the image (its reality) and what is external or secondary to it (montage).(1) As I will suggest later, science fiction films rely on the same criterion - the distinction between reversibility and non-reversibility - to differentiate between the human (the real) and the non-human (the simulated). An artificial being is reversible: its inside can function as its outside, and vice versa. A human being, on the other hand, is always diverging from self-identity.

For Wheeler and similarly minded critics an image turns into a spectacle when the distinction between image and montage collapses. It is difficult to take seriously Wheeler's resentment for CGI since his account of the dangerous and 'artificial' nature of digital images is virtually indistinguishable from his description of 'natural' or real images:

If spectacle is transparent, it is perhaps because the very opacity of light thrown on a screen through a series of coloured dyes, gels, or pixels manipulated by laser beams and the like is always an ephemeral construct. Constantly bursting forth in light, constantly decaying into momentary, flickering darkness, the transparency of the cinematic/video construct is at once alluring and dangerously seductive, a spectacle that we must control, before it controls us. (186)

Although Wheeler spends the rest of his book attempting to explain how digital manipulation turns an image into a spectacle, the above makes it clear that he treats as spectacle not only the image enhanced by means of special effects but any image insofar as it is constituted by light. The critique of special effects takes as its point of departure the assumption that film is essentially realistic i.e., representational. Since digitally manipulated images represent nothing but their own possibility or their process of production, it is not surprising that realists like Wheeler and Casebier consider them of marginal interest. Allan Casebier's examination of the phenomenological or realist nature of film images rests on a rather counter-intuitive account of what he calls the "idealist account of cinematic representation"(2), according to which film images remain purely denotative or locked in themselves. The 'idealists' emphasize the materiality of film (a film is made of sounds and visuals which do not refer to anything objectively existing), while the realists or 
phenomenologists insist on the representational nature of those visuals and sounds. Phenomenologists do not concern themselves with how images are constituted (whether they are made of real or digitally manipulated elements, for example) but rather with what these images reveal of the real world beyond themselves. For an idealist, however, what a film represents depends on, or reveals, the spectator's constructed beliefs or prejudices, but it does not reveal the real world. The distinction between real and digitally manipulated images is, therefore, merely a subjective distinction made by the spectator, revealing his personal way of apprehending an image. It is not a distinction between something real and something constructed simply because for the idealist everything in a film image is constructed. Therefore, the distinction between 'real' and 'digital' is irrelevant or nonexistent; it exists only from the point of view of the realist or the phenomenologist, who seeks the real referent of both the real and the digital image.

Wheeler and Casebier are afraid that new digital technologies underscore the act of perception itself (the image on the screen) at the expense of the object of representation (the thing off-screen the image supposedly stands for). In their view, once an image has been digitally manipulated, it multiplies itself. An image consisting of both real and computer-generated elements turns into something like an image within an image: the digital element is itself a simulation of an image - this already presupposes that only that which has been recorded by a real camera, as opposed to a virtual one, counts as an image - and this simulation of an image is then combined with the real element, the pure image. ${ }^{(2)}$ Digital technologies make the image self-referential by drawing attention to its very constitution or composition while de-emphasising its representational value.

In opposition to Wheeler and Casebier, Noël Carroll argues that the issue of what a film represents is not an ontological one at all. Cinematic representation is by nature 'nominal': "A shot is a nominal portrayal of a person, object or event when it represents a particular person, place or thing different from the person, place or thing that gave rise to the image" (my italics). Carroll subscribes to the "idealist" or presentational account of cinematic representation, according to which the distinction between real and digital is irrelevant: since all images present only themselves, a digitally enhanced image is as real (which should be distinguished from realistic) ${ }^{(3)}$ as one that is not digitally manipulated, or conversely, a real image is as 'artificial' as a digital image. Bukatman, another opponent of the realists' critique of special effects, goes one step further than Carroll, arguing that in fact simulation does not originate with the digital manipulation of images since all images - even those not manipulated digitally - are so self-sufficient and distant from the spectator that they are already simulacral. Bukatman's analysis situates the simulacrum not in a specific type of images (e.g., CGI) but in the historical transition to a world dominated by information technology:

Bodily experience and cognitive understanding were thus both supplemented and largely replaced by a reliance on vision within a simulacrum of the real. If the visual was now largely removed from the confirmation of haptic experience (a fundament of the information age), then the visual would become a hyperbolically self-sufficient source of knowledge. ("The Artificial Infinite" 252-253)

The shift in the importance of the two central senses - the shift from touch to sight, from body to vision - is precisely the transition from the real (the body) to the simulacrum (the image). In this view, simulation is equivalent to vision: all images, regardless of whether they are created with a real or a virtual camera, ${ }^{(4)}$ are already simulations of real, bodily experience.

The question of the value or function of special effects in film is, in fact, the new ground on which the old problem of representation is raised once again. The extensive use of special effects in SF films has conferred on this particular film genre a privileged status in this ongoing debate. Defending the pure visuality of SF film, Brooks Landon proposes that it is necessary to shift our understanding of narrative "from something conveyed with the semblance of a film to something conveyed by the mechanisms of film itself" (The Aesthetic of Ambivalence 63). The disparaging attitude toward special effects results from our tendency to ignore the visual nature of film and to think of SF film as merely illustrating the science fiction novel or story on which it is usually based. Referring to Christian Metz's "Trucage and the Film" ${ }^{(5)}$ Landon argues that "cinema is itself science fictional"(65) since "the language or grammar of film consists in great part of nothing but special effects, the visual trickery inherent in montage, wipes, cutting, close-ups, impossible camera placement, panning, zooms, slow motion, multiple exposures, and the virtually limitless possibilities of editing, matting, and so on"(90).

Special effects occupy a privileged phenomenological position insofar as in a world that is becoming increas- 
ingly oblique, invisible, distant, computerized, special effects dramatize or foreground the act of perception as such. By deconstructing perception - for instance, in compositing images digitally - by trying to create an artificial perception that approximates the fluidity of real perception, special effects serve as a reminder (perhaps even a nostalgic one, which would make them anachronistic inasmuch as special effects technology is of the future rather than of the past) of the sheer visibility of the world and of our ability to perceive it: "Cinematic affect is rooted in cinematic technology, but effects emphasize those underpinnings: if cinema is rooted in illusions of light, for example, then optical effects endow light with an overwhelming physicality" (Bukatman, "The Artificial Infinite" 271).

The constitutive ambiguity of special effects lies in the fact that, insofar as they are computer-generated they are part of the general trend toward invisibility (computer data is invisible), but their function is just the opposite: to return us to the origin of perception, the sheer joy of seeing, the pleasure of seeing for the sake of seeing. ${ }^{(6)}$ Many special effects recreate or illustrate the process of natural perception. Take, for example, digital compositing ${ }^{(7)}$ or "male" and "female" mattes. ${ }^{(8)}$ The supposedly "artificial" act of extracting an image from its natural background and incorporating it into a different context manifests the usually latent nature of natural perception as a process of selection.

An important consequence of the historical change in the function of special effects is the blurring of the distinction between the real and the unreal caused by "the narrowing of the gap between the depiction of technologically wondrous worlds and the very real technological wonders of film production"(Landon 70). The growing indistinguishability between the real and the unreal is no longer merely a common subject matter of SF films but is rather the real result of the continuing perfection of special effects technology. To the extent that special effects represent the imaginary while demonstrating what is possible and, in fact, real in production technology, they introduce an element of hyperreality (72). The hyperreal is the effect of combining an imaginary object of representation - e.g. the L.A. metropolis in Blade Runner--with very real means of representation (the latest achievements in special effects technology). SF films - films about the future and set in the future - challenge our understanding of the relationship between an object of representation and the means of representation. Special effects technology has created the conditions in which the distinction between an object of representation and the means of representation can no longer be taken for granted: the representation of the impossible must be already possible i.e., the object must already coincide with the means of its representation. The erasure of the distinction between them produces the hyperreal. Therefore, the hyperreal is pure presentation, the disappearance of any traces of the act of construction i.e., of representation. This, in turn, puts the real and the hyperreal in a new light. Now it becomes clear that the real is recognized by the traces of its construction i.e., by the gap separating the object of representation from the means of representation. By contrast, the hyperreal is recognized by the absence of such traces. The real is produced; the hyperreal is always already there.

Landon's study of time travel films in The Aesthetics of Ambivalence provides an example of the hyperreal or self-referential nature of SF films. Time travel is not just a subject matter of SF films but "cinema is itself a kind of time machine"(74). In SF films, time travel is both the object and the means of representation. The nature of SF film - and of film in general - is temporal and spatial displacement. Certain special effects reproduce or dramatize this constitutive characteristic of film. For example, compositing an image involves putting together images that have been shot at different times and locations. Thus, an individual image that has been digitally composited reproduces on a miniature scale (it functions as a metonymy of) the temporal and spatial discontinuity constitutive of film in general. In this way, SF film becomes self-referential on a formal rather than a thematic level. ${ }^{(9)}$

Special effects reveal the reflexive nature of the SF film genre which "almost inevitably seems to be about the movies precisely because of the ways in which its reliance on special effects implicates both the technology of film and the typical concern of most popular narratives with achieving a transparent realism"(Telotte 25). Science fiction's self-reflexiveness is also due to the "increased emphasis on mediation and the technology of reproduction - in effect, an imagery of film itself - in our recent science fiction films"(30). SF films dealing with the theme of reproduction or simulation - the simulation of reality or the creation of artificial beings are self-referential insofar as their medium (film as a technology of reproduction) coincides with their object of representation (reproduced reality or reproduced human beings). 
Although special effects attempt to approximate as closely as possible natural perception, or precisely because of this, they are generally examined as an instance of simulation. Accordingly, the rest of this essay will address the question of simulation from two points of view: simulation as a means of cinematic representation (special effects) and simulation as an object of cinematic representation (the representation of simulated worlds and beings).

Narrative has come to dominate the making of films but in its very beginnings cinema was not narrativedriven. The attraction of early films lied in their pure visual effect, in their presentation (rather than representation) of the world. Even more important than the growing sophistication of special effects has been the change in their function. Early filmmakers employed special effects to create a pleasant illusion, an imaginary world that defied the law of logic and probability or the laws of nature. Special effects were part of film magic, of the ability of film to create a world different from ours, to take us to fantastic places, as in Méliès' A Trip to the Moon. To create another, imaginary reality was more important than to manipulate the viewers' relationship with their own reality. The radical change in the function of special effects becomes particularly clear in contemporary SF films, where special effects are no longer used to represent imaginary worlds but rather to increase the realism of a certain representation.

Films like Starship Troopers, Total Recall, Terminator: Judgment Day demonstrate that special effects are almost never used to undermine the distinction between the real and the simulated but almost always used to increase the realistic effect of the representation. A contemporary film dealing with the typically postmodern problem of distinguishing the real from the simulacral will most probably not use special effects in its representation of the simulacral. The spectacular in SF films today strives to be as real as possible i.e., simulation is subordinated to the purposes of realism.

In the three films mentioned above the means of representation are simulacral (special effects) but the object of representation is reality. On the other hand, $\mathrm{SF}$ films whose subject matter is the corruption of the real by the simulacral tend to avoid using special effects to represent the simulacral: when the object of representation is a simulacrum, the means of representation are real. And rightly so. A simulation does not signal its difference from reality; therefore, the best way to represent a simulation is by representing it in exactly the same way one represents the real. To sum up: (1) special effects cinematography is a kind of simulation insofar as it involves the mixing and matching of real images filmed separately or of real and artificially created images; (2) special effects are used to increase the realism of a scene; (3) special effects are not used to represent the blurring of the distinction between reality and simulacrum. Simulation (special effects) is used to heighten the impression of realism; conversely, simulation itself cannot be represented through simulation (through special effects). Reality can be represented through simulation; however, simulation cannot be represented through simulation but only by realistic means of representation.

This accounts for the lack of special effects in eXistenZ and AI: Artificial Intelligence, both films dealing with a simulated reality or a simulated being. ${ }^{(10)}$ In eXistenZ, the lack of special effects in the representation of the game world simulates the simulacral nature of that world: since the game world cannot be distinguished from the real world, the only way to represent the game world faithfully is not to use special effects to mark it off from the real world. The same is true of Total Recall and Dark City, in both of which the protagonist is a man with an invented identity, whose memories have been imprinted on him. Visually there is no difference between the representation of the world of the character before and after he discovers his real identity. Both the representation of John Murdock's simulated life with his fake wife Ana Murdock and the parallel representation of Quaid's simulated life with his fake wife Lori, are realistic. In fact, the phrase "total recall" is used in the film to signify both the recalling of a package of simulated memories bought from the corporation Total Rekall and the recalling of Quaid's real identity which starts happening before the fake memory of a vacation on Mars has been implanted in his mind.

Total Recall and Dark City demonstrate that the most authentic representation of a simulacrum is one that disguises the simulacrum perfectly, a realist representation that does not draw attention to the reality of the object of representation. Simulation is unrepresentable precisely because it is identical to reality. However, since simulation cannot be represented visually, it has to be represented indirectly.

On the one hand the simulacral cannot be represented by means of itself but must be always represented as the real. On the other hand some sort of difference (the slightest one) must be suggested between reality 
and simulation (the audience must be made aware of the simulacrum's existence), a film usually resorts to non-cinematic means. Both eXisten $Z$ and $A I$ use the narrative structure to suggest the artificiality of the game world and the artificiality of the robot child. In eXistenZ, the protagonists (Ted, "the bodyguard" and Allegra, "the computer game designer") enter and exit the game world several times. If it were not for these pauses in the game (pauses in the plot), the audience could not distinguish between reality and simulation since both are represented visually in exactly the same way.

At the end of Total Recall, Quaid turns on the reactor which provides air to the mutant inhabitants of Mars. But as he looks up at the blue sky for the first time, he is still plagued by the suspicion that this is only a dream, part of the simulated memory he bought at Total Rekall, the happy ending of his paid simulated vacation to Mars. Again, there is nothing in the visual representation of Mars that would help one identify it as real or simulated. The only doubt comes from within the plotline, from the fact that at a certain point in the film Quaid has visited Total Rekall.

The suggestion of a blurring of the distinction between reality and simulation remains purely rhetorical or theoretical in Total Recall, Dark City and eXistenZ: characters argue about the reality of their experiences but there is no cinematic signifier of the difference between reality and simulation. The simulacrum is part of the narrative, never becoming part of the cinematography of the film. All we know about the artificial nature of the robot child in $A I$ derives from the plotline, not from the visual representation of David. With the exception of a few occasions when we see the robot boy (David) at the dining table, unable to eat as a real boy and in fact becoming sick when trying to do so, and a few glimpses of his insides on the operating table, there is nothing to distinguish David's body from the body of a real boy. Similarly, in eXistenZ, the body cannot serve as a criterion for distinguishing the supposedly real Allegra and Ted from the game characters they encounter in the game world.

If special effects are a form of simulation (insofar as they attempt to create a realistic image of something that does not exist) the use of such simulation in the representation of a simulated reality--the representation of simulation by means of simulation--is bound to fall short of the object of representation. Simulation can and should be represented only by natural representational means, not through another form of simulation as in Dark City, for example. In that film special effects are used to represent the simulated world, the world "tuned" by the Strangers. The use of miniature models, stop-motion, and other special effects makes the simulated world so obviously simulated that it undermines the reality of the simulation and the anxiety and disorientation the protagonist, as well as the viewers, are supposed to feel. We feel much more unsettled and disoriented in eXistenZ, which provides us with no visual markers that would help us keep reality and simulation apart, than in Dark City, which represents the simulation directly.

So far it appears that simulation cannot be represented through simulation. However, in The Matrix simulation is both the object and the means of representation. The film demonstrates the difference between the virtual and the real in purely cinematic terms. ${ }^{(11)}$ In representing the virtual world, The Matrix attains a certain degree of self-referentiality. As soon as Neo swallows the pill Morpheus offers him, he finds himself in an empty frame (the only furniture being a plush armchair and a TV set) while Morpheus explains to him that he has been living in a virtual world (the matrix).

This scene, as well as the following several scenes, fulfills two functions: on one hand, a narrative function (representing the illusory nature of the world Neo thought was real) and on the other hand, a self-referential function insofar as the scenes in question draw attention to the very techniques used in their shooting (mattes, blue screen, bullet time photography, digital compositing etc.). Digital compositing allows different images to be shot separately and then combined in the same shot, some of them positioned in the foreground, others in the background, creating a complicated, layered image.

The virtual world of the matrix in which Neo finds himself, while he watches images of the destruction of the real world on the TV screen, is also the virtual or digital world that makes possible the filming of the very scenes in The Matrix that expose the virtual nature of Neo's world. There is a perfect correspondence (or rather overlapping) between the means of representation and the object of representation, between the digital compositing of images used in the filming of The Matrix and the simulation of reality, of which the protagonist is made aware. Digital compositing special effects are used to create a realistic representation of the virtual world of the matrix. The means of representation practically coincide with (rather than merely 
corresponding to) the object of representation: the virtual, simulated world is represented by virtual means (virtual camera, digital compositing).

These scenes reveal the illusion of what Neo believed to be the real world but they do so only by creating another illusion (insofar as in reality Neo and Morpheus have been first filmed against another background and their images later digitally combined with a completely neutral, white background that appears to envelope them on all sides). Unlike eXistenZ and Total Recall, here the simulacral is represented through the simulacral.

However, special effects are used only to point out the simulacral nature of what Neo thought was the real world. The other occasions when we catch a glimpse of the simulated world there are no special effects used to suggest that this world is not the real world. In this sense, the special effects used in the scenes discussed above (Morpheus explaining the matrix to Neo) serve a narrative function: the simulation must be pointed out to Neo in order to motivate him to act. Because these scenes draw attention to the difference between the real and the simulated, they undermine the reality of the simulacrum. The simulated world is represented more in accordance with its logic in those scenes in which the edges of the virtual world are not made so obvious (for example, Neo's visit to the psychic, who turns out to be an ordinary woman living in an apartment building).

The use of special effects in the representation of T-1000, the evil terminator in Terminator 2: Judgment Day, produces a similar kind of self-referential framework in which the nature of the cyborg (the simulated being) coincides with the nature of the means used to represent him (the specific special effects used). T-1000 is a cyborg made of liquid metal, capable of morphing into anything he touches. When attacked, he disintegrates into pieces which are inevitably reintegrated. On several occasions T-1000 is shot, which causes his body to split into two down to his waist. The two parts hang apart from each other for a while and then morph back into one, recovering the unity of the whole. T-1000 has no inside or outside: he is absolutely reversible. Even when he is blown up into little pieces of liquid metal, the cyborg is capable of reconstituting himself without any loss. This is precisely the nature of digital information: "Digital information can be copied and transmitted repeatedly with no loss of detail, making it ideal for special effects production where images need to be copied and combined many times" (Rickitt 309).

The character of T-1000, a simulated being, embodies the very nature of simulation: self-sufficient, selfreferential, reversible. Digital special effects are used to represent the digital (virtual) nature of the cyborg. While T-1000 remains as invincible and unalterable (except superficially) as a digital image (which can be used and reused infinitely without a significant loss of quality), the good terminator exhibits his closer proximity to humanity through his vulnerability, his ability to be wounded or maimed. Although he appears convincingly human, he remains a less perfect simulation of a human being than T-1000. Terminator uses artifice (CGI) to represent artifice (the cyborg T-1000). The specific special effect used - "morphing" coincides with the object of representation, which is exactly the cyborg's morphing capacity. Special effects are not used as 'tools' in the representation of a certain reality; they are the reality they are presenting: they are finally liberated from the necessity to serve the narrative or merely enhance the object of representation.

So far I have discussed simulation as a means of cinematic representation, specifically the way in which simulation (special effects) produces a certain self-reflexiveness in the SF film genre. I will now consider what happens when simulation is the object of cinematic representation, either as a simulated reality or a simulated being. In eXistenZ the only way to mark the end point of the real and the entry point into the simulacral is to show the protagonists "plugging" themselves into the game or, in a few instances, "pausing" the game to return to reality. We first become aware of the blurring of the distinction between the real and the game world right after Allegra and Ted start playing. Once they are transported into the virtual world of the game, the first thing they check is whether their game bodies have bioports, a test that would be absolutely unnecessary if they were simply playing a game.

Obviously, a player who suspects that his real body does not remain outside the game but is transported within the game and can therefore assume any form - including one lacking a bioport - doubts, from the very beginning, that he is merely playing a game. If the bioport is the connection between the real and the game world, the possibility of not having a body with a bioport within the game is tantamount to not being able to stop playing the game. The need to make sure that the real body is perfectly reproduced in the game body 
(the simulated one) suggests that the relationship between reality and simulation is not one directional, that the real body is not in control of the simulated body, that the return to reality is not assumed or guaranteed in any way.

Since entering the game and returning to reality requires the same kind of body - a body with a bioport it becomes irrelevant whether a real body is entering the game or a simulated body is returning to reality. The real world has no ontological priority over the game world since to return to the real world the same means are required as to leave it. Thus, the difference between the real world and the game world is erased even before the game has started. Allegra and Ted appear to be real as they comment on the quality of characterization used in the game or on the sophistication of the characters' dialogue.

However, it becomes clear by the end of the film that they, too, were merely game characters in another game appropriately called Transcendenz. Nevertheless, they are far more sophisticated game characters than the majority of the characters inhabiting the game world of eXistenZ. Their sophistication lies in their ability to feel suspicious of their own reality. They are the perfect simulation of human beings since only human beings are capable of doubting their own reality. Ted's game character, for example, experiences exactly what real human beings experience when they enter and leave a virtual reality: Ted feels worried about his real body, he reports feeling vulnerable, disembodied. When he pauses eXistenZ to return to reality, he finds himself unable to tell whether he is really back in the real world or he is still in the game. All of these anxieties and fears are, of course, not real since Ted is eventually revealed to be a game character. However, his game character simulates perfectly the normal human response to the disorientation and insecurities that mark the transition from a real to a virtual world. Preoccupied with his own reality and desperately wanting to be real, Ted's game character is a perfect simulation of a human being because only a human being is capable of positing his own reality as a problem. To be human is to want to be real. The most successful simulation of the human is the simulation of the human desire for the real.

The objective of the game eXistenZ is to make the central character feel more real than the rest of the game characters. Similarly, $A I$ asks whether a "mecha" could become an "orga." A perfect simulacrum such as David, the robot child, can become real only if it exhibits the most human characteristic: the ability to dream, to wish for impossible things. By dreaming about the blue fairy who will turn him into a real boy, David has already become real or human (the two are considered identical in the film). What makes the simulated being real is its desire to be real: the desire to be real cannot itself be simulated, which proves that it is a reliable criterion for differentiating between the real and the simulated. However, the positing of the desire to be real as the distinguishing mark of the real makes the real lacking in itself. The real is defined as that which lacks reality, that which wants to become real.

By analogy, the simulacrum is full of itself, completely real, completely itself. Thus, reality and simulation exchange places: simulation is fully real, while the real is not entirely real. Put differently, simulation is total self-identity, whereas the real never fully coincides with itself. The real is that which diverges from itself, wants to be different from itself. David, the artificial being, proves that he is real (human) by wanting to be something different from himself, to be different from a "mecha." Paradoxically, David's desire to be real presupposes that he is artificial, but at the same time his desire to be real, a desire for the impossible, is precisely what makes him real. No special effects are used in the representation of David since the purpose is to show that he is real. Since special effects generally tend to increase the realism of the object of representation, they produce a hyperreal effect: they make the object of representation appear more simulated than real. To represent David as real rather than artificial, the filmmaker has wisely chosen not to use special effects. By contrast, an older generation female mecha (less perfectly simulating a human being than David) is represented in the opening scene of the film with the help of special effects, which allows us to see her human face come apart to reveal the mechanics underneath. This deconstruction of the mecha makes her appear to us realistically artificial, which underscores further her simulacral nature.

In general, the more perfect the simulation, the fewer special effects are used since by underscoring the difference between the reality and the simulation special effects inadvertently draw attention to the imperfection of the simulacrum (the female mecha). The same principle holds in the representation of simulation in eXistenZ: the game world is connected to the real world in a too obvious way, through something resembling an umbilical cord. The virtual is not represented as a clean, technologically advanced, autonomous 
space but almost as an extension of the human body. Since the simulated world of the game looks and feels as real as the real world, the only way to establish its simulacral nature is not through disguising the transition between the two but through rendering it as literal as possible (the organic or the real is obvious; the simulacral or the technological is unobtrusive, subtle).

eXisten $Z$ shows the ultimate form of simulation to be the construction of a realistic distinction between the real and the simulacral within an already simulated world such as the virtual world of a game. The meta-game Transcendenz has the objective of convincing the player that she is real whereas everyone else is a game character, a simulation. The player wins when she eliminates all game characters, thus affirming her own reality. The aim of the game is to make the players forget that they, too, are game characters, to create in them the illusion of their own reality. The "most effective deformation of reality" (the crime with which the designer of Transcendenz is charged at the end of the film) is achieved by reproducing most faithfully one of the defining characteristics of the real, doubt. The ultimate form of simulation is achieved not when the player cannot distinguish between reality and the game, but when he cannot distinguish between the real and the simulacral within the game, when the distinction between reality and simulation is replicated within the simulation. A simulation approaches reality when it reproduces within itself the very distinction between reality and simulation. The success of Transcendenz is due to its power to pose a certain part of itself as real, outside the game, and another part as simulated, within the game.

To what extent does an artificial being's awareness of its own artificiality affect its ontological status? Can a simulation be aware of itself without thereby becoming a reality? Is the desire to be real - self-awareness - a necessary or sufficient condition for determining the reality of something? These are questions about simulation as an object of cinematic representation. The answers determine the status of simulation as a means of representation and thus the function of special effects. SF films can be divided into two groups depending on how they represent simulation: those that represent simulation through simulation (The Matrix, Dark City, Terminator 2: Judgment Day) thereby stressing the self-reflexive nature of the genre, and those that purposefully avoid using special effects so as to erase any visual marks distinguishing simulation from reality (eXistenZ, AI). Films in the former group use special effects to achieve a realistic cinematic representation of simulation. When simulation is represented through simulation the effect is an increased sense of realism. In this sense, The Matrix is a realistic film. Conversely, films in the latter group, which dispense with special effects in order to live up to the logic of simulation (simulation is indistinguishable from reality; therefore, its representation must also be indistinguishable from the representation of reality) are, paradoxically, unrealistic. The reason for this is that simulation can be realistically represented only when we, the viewers, can distinguish simulation from reality i.e., simulation can be represented at all only if it is not represented according to its own logic. The only possible representation of simulation in cinema is one that simulates simulation's true nature.

\section{Notes}

1. The question whether the reality of an image is something intrinsic to the image or can be manipulated in the same way that relationships between images can be manipulated reopens the old philosophical debate over the reality of perceptions (and at the same time raises it to a second degree insofar as it inquires into the correct procedures for establishing the reality of an image i.e., the reality of an artificial construct, rather than the reality of natural perception). In her book Philosophy through Film Mary M. Litch examines two of the films I discuss here, Total Recall and The Matrix, as exemplifying the Descartes-Berkeley debate over what constitutes a genuine perception. While Descartes argues that the reality of a perception is always contextual (it depends on the other perceptions preceding and following it), Berkeley objects that the genuineness of a perception is intrinsic to the perception. See especially the first chapter entitled "Skepticism" (7-37).

2. See, however, Lévy for a positive interpretation of the virtual. Lévy rejects the association of the virtual with the false or the illusory. Following Bergson and Deleuze, rather than Baudrillard, Lévy asserts that the virtual "is by no means the opposite of the real. On the contrary, it is fecund and powerful mode of being that expands the process of creation, opens up the future, injects a core of meaning beneath the platitude of immediate physical presence"(16). He examines the virtual in terms of the already cliché idea 
of deterritorialization, challenging the idea of being as presence (the Heideggerian "being-there").

3. On the difference between "real" and "realistic" see Jacques Aumont. "A realistic image is not necessarily one which produces the illusion of reality. A realistic image is an image that provides the maximum information about reality. In other words, if analogy concerns the visual, the domain of appearances, and visible reality, realism concerns the information conveyed by the image, it conveys understanding and thinking" (Aumont 157). 4. "The hypothetical camera used to film animation and environments created within the computer. The virtual camera is not actually a camera but rather the 'device' used to describe the viewpoint that the computer will use when deriving information about the digital world during the process of rendering. Virtual camerascan be programmed to use different types of lenses and animated to move like real cameras"(Rickitt, Glossary 312). 5. Cinematographic trucages are tricks or special effects accomplished by means of the camera. 6. Some critics have established a connection between special effects and the sublime. Landon suggests that special effects can be examined as an embodiment of the "techno-sublime"'(68). He observes that the most memorable special effects sequences in movies usually interrupt the narrative rather than advancing it i.e., they function as a pure spectacle that seduces the audience in looking at them for the sake of looking. Starting from Christian Metz's idea that "cinematic identification occurs around the filmic apparatus itself - specifically, with the camera" (Bukatman 91) rather than with the protagonist, Scott Bukatman observes that the use of a "virtual camera" provides the viewer with experiences that clearly transcend the physical limitations of his point of view but which are still experienced subjectively. One of the characteristics of the sublime is precisely the feeling of transcendence which the subject experiences subjectively rather than as something abstract. Following Landon's defence of special effects' self-sufficiency and independence from narrative, Bukatman suggests that narrative has become merely a kind of mediation, which is no longer needed since special effects offer us an immediate experience of virtual realities. 7. A composite is "[a]ny image that is made up from a combination of two or more elements filmed at different times or places" (Rickitt, Glossary 308). 8. A matte is "[a]ny form of mask that prevents light from reaching and exposing areas of the film. Mattes always exist in two complementary parts; one matte allows exposure on one part of the film and prevents it in another, while a counter-matte covers the already exposed area and allows the rest of the frame to receive a different image. A matte and its counter-matte are often referred to as a male and female matte" (Rickitt, Glossary 310). 9. Just as the time of the film differs from itself, the time of an individual image differs from itself. This differing from itself has been interpreted by Paul Virilio as part of the trend toward hyperreality: "In fact we are moving from an extensive, historical, time scale towards an intensive temporality of ahistorical immediacy. If time is history, speed is only its hallucination, a perspectival hallucination which undoes the meaning/direction (sens) of narrative and action for the sake of pure sensation. The cinematographical processbring $[\mathrm{s}]$ about a densification, a saturation, of space and time" (Virilio qtd. in Kuhn 173). 10. According to Georg See len "every artificial being is a revolt of the movie image against itself and against the gaze"(16). An artificial being is an image that has become aware of its own artificiality. 11. See Springer 210-218 for a discussion of the different camera work used in the representation of real and virtual reality: "Cyberspace is characterized by computer graphics, rapid camera movement, and extreme angles, while the 'real' world is live-action footage shot pedantically in conventional Hollywood style"(210).

\section{References}

\section{Works Cited}

AI: Artificial Intelligence (2001). Directed by Steven Spielberg. Starring Haley Joel Osment, Jude Law, Frances O'Connor.

Alien Zone II: The Spaces of Science-Fiction Cinema. Ed. Annette Kuhn. London: Verso, 1999.

Aumont, Jacques. The Image. Trans. Claire Pajackowska. London: British Film Institute, 1994.

Bukatman, Scott. "The Artificial Infinite: On Special Effects and the Sublime" in Alien Zone II, 249-276.

. "Cybersubjectivity and Cinematic Being." Crisis Cinema: The Apocalyptic Idea in Postmodern

Narrative Film. Ed. Christopher Sharrett. Washington, DC: Maisonneuve Press, 1993. 77-103. 
Carroll, Noël. Theorizing the Moving Image. Cambridge: Cambridge UP, 1996.

Casebier, Allan. Film and Phenomenology: Toward a Realist Theory of Cinematic Representation. Cambridge: Cambridge UP, 1991.

Dark City (1998). Directed by Alex Proyas. Starring Rufus Sewell, Kiefer Sutherland, Jennifer Connelly.

eXistenZ (1999). Directed by David Cronenberg. Starring Jennifer Jason Leigh, Jude Law, William Dafoe.

Landon, Brooks. The Aesthetics of Ambivalence: Rethinking Science Fiction Film in the Age of Electronic (Re)production. Greenwood Press: Westport, Connecticut, 1992.

Lévy, Pierre. Becoming Virtual: Reality in the Digital Age. Trans. Robert Bononno. New York: Plenum Trade, 1998.

Litch, Mary M. Philosophy through Film. New York: Routledge, 2002.

The Matrix (1999). Directed by Andy and Larry Wachowski. Starring Keanu Reeves, Laurence Fishburne, Carrie-Ann Moss.

Rickitt, Richard. Special Effects: The History and Technique. New York: Billboard Books, 2000.

See len, Georg. "Dream Replicants of the Cinema: Passage through Old and New Moving Images." Artificial Humans. Eds. Rolf Aurich, Wolfgang Jacobsen, Gabriele Jatho. Trans. Stephen Locke, Ishbel Flett, Pauline Cumbers. Berlin: Jovis, 2000.

Springer, Claudia. "Psycho-Cybernetics in Films of the 1990s" in Alien Zone II 203-218.

Starship Troopers (1997). Directed by Paul Verhoeven. Starring Casper Van Diem, Dina Meyer, Denise Richards.

Telotte, J.P. Science Fiction Film. Cambridge: Cambridge UP, 2001.

Terminator 2: Judgment Day (1991). Directed by James Cameron. Starring Arnold Schwarzenegger, Linda Hamilton, Edward Furlong.

Total Recall (1990). Directed by Paul Verhoeven. Starring Arnold Schwarzenegger, Rachel Nicotin, Sharon Stone.

Virilio, Paul. "Cataract Surgery: Cinema in the Year 2000." Alien Zone: Cultural Theory and Contemporary Science Fiction Cinema. Ed. Annette Kuhn. London: Verso, 1990. 169-174.

Wheeler, Dixon Winston. The Transparency of Spectacle: Meditations on the Moving Image. Albany: SUNY Press, 1998.

\section{Author Information}

Temenuga TRIFONOVA (MA Sofia University, PhD Buffalo) is currently pursuing a MFA in Film at the University of California. Her publications include "Time and Point of View in Contemporary Cinema" in CineAction and "The Question of the Appendix: The Kantian and the Inhuman Sublime" in International Studies in Philosophy. She is the co-translator of Northrop Frye's Myth and Metaphor into Bulgarian. 